\title{
Intercomparison of Four Commercial Analyzers for Water Vapor Isotope Measurement
}

\author{
XUE-FA WEN \\ Key Laboratory of Ecosystem Network Observation and Modeling, Institute of Geographic Sciences \\ and Natural Resources Research, Chinese Academy of Sciences, Beijing, China
}

\section{XUHUi LeE}

Yale-NUIST Center on Atmospheric Environment, Nanjing University of Information Science and Technology, Nanjing, China, and School of Forestry and Environmental Studies, Yale University, New Haven, Connecticut

\author{
XiaO-Min Sun, Jian-Lin Wang, Ya-Kun Tang, Sheng-Gong Li, and Gui-Rui Yu \\ Key Laboratory of Ecosystem Network Observation and Modeling, Institute of Geographic Sciences \\ and Natural Resources Research, Chinese Academy of Sciences, Beijing, China
}

(Manuscript received 29 November 2010, in final form 30 August 2011)

\begin{abstract}
The $\delta^{18} \mathrm{O}$ and $\delta \mathrm{D}$ of atmospheric water vapor are important tracers in hydrological and ecological studies. Isotope ratio infrared spectroscopy (IRIS) provides an in situ technology for measuring $\delta^{18} \mathrm{O}$ and $\delta \mathrm{D}$ in ambient conditions. An intercomparison experiment was carried out with four commercial IRIS analyzers to characterize their performance and transferability of calibration methods. Over a 15-day atmospheric measurement, during which the water vapor concentration ranged from 14 to $27 \mathrm{~mol} \mathrm{~mol}^{-1}$ and the isotopic ratios spanned about $90 \%$ and $13 \%$ for $\delta \mathrm{D}$ and $\delta^{18} \mathrm{O}$, respectively, these analyzers tracked the natural variability in ambient conditions very well and achieved an average difference between one another within $2 \%$ for $\delta \mathrm{D}$ and within $0.1 \%$ for $\delta^{18} \mathrm{O}$ after calibration at appropriate frequencies. Two of the calibration methods (discrete liquid water injection and continuous dripping) agreed with each other within the tolerance thresholds of $2 \%$ for $\delta \mathrm{D}$ and $0.1 \%$ for $\delta^{18} \mathrm{O}$. The Rayleigh distillation technique appeared to be acceptable as a calibration standard for $\delta \mathrm{D}$ but not for $\delta^{18} \mathrm{O}$. The $\delta \mathrm{D}$ measurements were less prone to concentration dependence errors than the $\delta^{18} \mathrm{O}$ measurements. The concentration dependence underscores the importance of using a calibration procedure at multiple mixing ratios to bracket the range of natural variability.
\end{abstract}

\section{Introduction}

The $\delta^{18} \mathrm{O}$ and $\delta \mathrm{D}$ of atmospheric water vapor provide rich information on the hydrological cycle and gaseous exchange processes between the terrestrial vegetation and the atmosphere (Gat 1996; Yakir and Sternberg 2000). Recent development of isotope ratio infrared spectroscopy (IRIS) has made it possible to make in situ, continuous observations of the $\delta^{18} \mathrm{O}$ and $\delta \mathrm{D}$ of atmospheric water vapor, providing an attractive alternative

Corresponding author address: Xue-Fa Wen, Institute of Geographic Sciences and Natural Resources Research, Chinese Academy of Sciences, A11 Datun Road, Beijing 100101, China.

E-mail: wenxf@igsnrr.ac.cn to the traditional isotope ratio mass spectrometry (IRMS; see Kerstel and Gianfrani 2008; Helliker and Noone 2010). Currently, at least three commercial IRIS instruments for water vapor isotopic measurement are in use, including tunable diode laser absorption spectroscopy [TDLAS; by Campbell Scientific Inc., Logan, Utah (see Lee et al. 2005; Wen et al. 2008; Griffis et al. 2010)], wavelength-scanned cavity ring-down spectroscopy [WS-CRDS; by Picarro, Inc., Sunnyvale, California (see Crosson 2008; Gupta et al. 2009)], and off-axis integrated cavity output spectroscopy [OA-ICOS; by Los Gatos Research, Mountain View, California (see Baer et al. 2002; Wang et al. 2009; Sturm and Knohl 2010)]. In addition, several dedicated research instruments have been available for some time now (Griffith et al. 
2006; Kerstel et al. 2006; Sayres et al. 2009; Dyroff et al. 2010).

All of the IRIS instruments aim to maintain accuracy that is traceable to international scales and have high enough precision to track the natural variability of $\delta \mathrm{D}$ and $\delta^{18} \mathrm{O}$ in ambient conditions. An ideal instrument should be free of concentration dependence effects (Schmidt et al. 2010), meaning that its measurement should not change with the changing water vapor mixing ratio at a constant isotopic composition. However, concentration dependence is a source of error in a TDLAS analyzer (Lee et al. 2005). The water isotope ratios measured with a WS-CRDS analyzer are a function of water vapor mixing ratio over the range of 3-26 mol mol${ }^{-1}$ (Brand et al. 2009). Another WS-CRDS analyzer shows no dependence of the isotope ratios on the water vapor mixing ratio for mixing ratio values between 12 and $28 \mathrm{~mol} \mathrm{~mol}^{-1}$ only after careful spectral fitting to remove the concentration dependence errors (Gupta et al. 2009). Pronounced concentration dependence for both $\delta \mathrm{D}$ and $\delta^{18} \mathrm{O}$ exists over the mixing ratio range of 2-27 mol mol ${ }^{-1}$ for an OA-ICOS analyzer (Sturm and Knohl 2010). In a study involving a research prototype, Iannone et al. (2009) found no concentration dependence for $\delta^{17} \mathrm{O}$ and $\delta^{18} \mathrm{O}$, but a significant concentration dependence for $\delta \mathrm{D}$ with the mixing ratio values less than $1.5 \mathrm{~mol} \mathrm{~mol}^{-1}$. The dependence on water vapor mixing ratio, if left uncorrected, will compromise the overall measurement accuracy.

The concentration dependence problem also affects instrument precision (Iannone et al. 2009). The precision of TDLAS analyzers degrades with decreasing water vapor mixing ratio (Lee et al. 2005; Wen et al. 2008). The short-term precision is not necessarily the limiting factor of an instrument's performance (Sturm and Knohl 2010). In fact, the study of Sturm and Knohl (2010) found that the concentration dependence of the isotope ratios is the main factor limiting the long-term precision.

The existing calibration methods for IRIS vapor analyzers fall into three categories, all of which aim to align the IRIS signals to the international Vienna Standard Mean Ocean Water (VSMOW)-Standard Light Antarctic Precipitation (SLAP) scale (Gonfiantini 1984; Hut 1987; Gröning 2004). The first method involves the use of a Rayleigh distillation device. The vapor exiting the device has lower isotopic compositions than the liquid water reservoir in it, and over time both the vapor and the liquid become progressively enriched. Several research groups have used the stream of moist air generated by a dewpoint generator as a vapor standard to calibrate the analyzer, relying on the assumption that the generated water vapor maintains the isotopic ratios that follow the
Rayleigh distillation prediction (Lee et al. 2005; Wen et al. 2008; Wang et al. 2009; Baker and Griffis 2010). However, a small but systematic bias from the Rayleigh line is evident, suggesting that the dewpoint generator is not a perfect Rayleigh distillation device (Wen et al. 2008). In a related study, two homemade bubblers were deployed as Rayleigh distillation devices to generate two reference standards with different isotopic compositions (Iannone et al. 2010), and calibration was achieved by interpolating between the two standards, which is a common practice used in mass spectrometer analysis. The error arising from the mismatch in the delta values between the sample and the calibration standard is sometimes referred to as the stretching of the delta scale. Interpolation between two or more standards with different delta values will remove this error.

In the second and also the most popular method, liquid water is injected into an evaporation flask that is supplied continuously with dry air. In the flask, evaporation occurs instantly and completely to prevent any fractionation, so that the moisture stream exiting the flask has isotope ratios that are presumably identical to those of the source liquid water feed, the latter of which can be measured accurately according to the VSMOWSLAP scale. The first such device, called a dripper, consists of a syringe pump that delivers the liquid water slowly into an evaporating flask supplied with dry air (Lee et al. 2005; Wen et al. 2008). The liquid water and the dry airflow rates are adjusted dynamically to ensure that the generated vapor tracks the ambient water mixing ratio. This design can be used for water mixing ratios in the range of $0.4-35 \mathrm{~mol} \mathrm{~mol}^{-1}$. Another dripper design is based on the same concept except that a nebulizer is used to deliver the liquid water (Iannone et al. 2010; Sturm and Knohl 2010). In a study that covers a broad range of mixing ratios, two dripping systems were used for mixing ratio values less than $5 \mathrm{~mol} \mathrm{~mol}^{-1}$ and two bubblers were used for measurements when the mixing ratio exceeds $5 \mathrm{~mol} \mathrm{~mol}^{-1}$ (Iannone et al. 2010). Use of two dripping systems or two bubblers with different water standards enables the researchers to account for the stretching of the delta scale during a two-point deltascale calibration procedure, as recommended by the International Atomic Energy Agency (IAEA; Gonfiantini 1984; Hut 1987). Another dripper device is designed for the water vapor mixing ratio up to $30 \mathrm{~mol} \mathrm{~mol}^{-1}$, and routine calibrations are made at $11 \mathrm{~mol} \mathrm{~mol}^{-1}$ with a linearity calibration to correct for the mixing ratio dependence (Sturm and Knohl 2010). These design ideas have now been developed into a commercial vapor calibration device [the Water Vapor Isotope Standard Source (WVISS) model, Los Gatos Research, Mountain View, California (Dong and Baer 2010)]. 
The third calibration method is a liquid autosampler coupled with an evaporator as it is often deployed in liquid IRIS analyzers (Lis et al. 2008; Brand et al. 2009; Schmidt et al. 2010). Discrete multiple known water standards are injected through a septum into an evaporator isolated from the sample cell. After evaporation is completed, the moisture is then flushed with carrier dry air to the sample cell for calibration. By applying a stretching factor in the delta-scale calibration procedure, the isotopic ratio of water vapor can be scaled using a linear fit of the true versus the measured delta values of the standards (Gonfiantini 1984; Hut 1987).

The overall performance of an IRIS analyzer can also be evaluated by comparing against other independent measurements. An intercomparison was made of an OA-ICOS analyzer with a WS-CRDS analyzer in laboratory-controlled conditions and with cryogenic vapor trapping-IRMS analysis in field conditions (Apodaca et al. 2009). Comparison against cryogenic vapor trappingIRMS analysis has also been reported by several other groups (Lee et al. 2005; Wen et al. 2008; Schmidt et al. 2010; Iannone et al. 2010). The equilibrium vapor values of rainwater offer an independent verification of the in situ data (Lee et al. 2006; Wen et al. 2010). In an in situ measurement using one OA-ICOS analyzer and one WS-CRDS analyzer, agreement between the two analyzers was found to improve with increasing mixing ratio (Galewsky et al. 2009). An intercomparison of four OA-ICOS analyzers among each other for liquid water isotopes reveals reproducibility from $\pm 0.56 \%$ o to $\pm 1.80 \%$ for $\delta \mathrm{D}$ and from $\pm 0.10 \%$ o to $\pm 0.27 \%$ for $\delta^{18} \mathrm{O}$ (Penna et al. 2010). It is not yet known if vapor IRIS analyzers can achieve similar or better reproducibility in field conditions. In another performance test on OA-ICOS and WS-CRDS liquid analyzers relative to IRMS, large differences were found for both untreated and cleaned leaf water samples by as much as $46 \%$ for D and $15.4 \%$ for ${ }^{18} \mathrm{O}$ (West et al. 2010).

In this paper, we report the results of an intercomparison experiment using four IRIS analyzers produced by the three major commercial brands described below. They include one analyzer from Campbell Scientific [model TGA100A (CS)], two analyzers from Picarro [models L1115-i (P5) and L1102-I (P2)], and one analyzer from Los Gatos Research [model DLT-100 (LS)]. Analyzer CS was manufactured in 2006, and analyzers P2, P5, and LS were manufactured in 2010. Three different methods were used to calibrate these measurements. A combination of ambient and laboratory experiments created large dynamic ranges of mixing ratio (1.5$27.4 \mathrm{~mol} \mathrm{~mol}^{-1}$ ) and isotope ratios (from $-200 \%$ to $-49 \%$ for $\mathrm{D}$ and from $-27.9 \%$ to $-6.7 \%$ for ${ }^{18} \mathrm{O}$ ). Our specific objectives are 1) to evaluate the relative accuracy among these analyzers, 2) to quantify the dependence of accuracy and precision on humidity, and 3) to identify the appropriate calibration strategy for long-term unattended operation. An ideal calibration method would be to generate multiple delta values over a range of mixing ratios expected of the ambient conditions. In this way, both issues of the delta scale stretching and the concentration dependence would be addressed. The above-mentioned methods only perform one of the two, and the question remains as to whether the calibration targeting either the delta stretching or the mixing ratio dependence provides more accurate results. Other sources of uncertainty include the impurity of the carrier's dry air that is either produced by a dry-air generator (model MDH1-FLE; Twin Tower Engineering, Broomfield, Colorado) or supplied by a bottle of synthetic air, incomplete evaporation within the evaporating flask, and fractionation associated with tube and chamber materials. Although these uncertainty sources were not dealt with explicitly here, the intercomparison of different calibration methods should help to put a bound on the overall impact of these operational imperfections on the measurement. Our work appears to be the first systematic attempt to compare multiple analyzers and to determine if the various calibration methods are truly transferrable with one another or if after these calibrations the measurements will agree with each other.

\section{Experimental}

\section{a. Analyzers, sampling, and calibration systems}

The instruments were housed in a room whose temperature fluctuated in the range between $26.4^{\circ}$ and $28.6^{\circ} \mathrm{C}$. All of the sampling tubes were Teflon to avoid the possibility of fractionation (Sturm and Knohl 2010).

The schematic diagram of the CS analyzer, its principle of operation, and its calibration procedure were described elsewhere (Lee et al. 2005; Wen et al. 2008). In brief, the analyzer was configured with a six-intake manifold, with three air sample intakes and three calibration gas intakes, including two calibration streams (S1 and S2) generated by a dripper (dripper A). In this study, two of the air intakes were blocked, and the flow rate of the third air intake was $0.57 \mathrm{~L} \mathrm{~min}^{-1}$ standard temperature and pressure (STP). A subsample $\left(0.2 \mathrm{~L} \mathrm{~min}^{-1}\right.$ STP) was drawn into the analyzer's sample cell. The signals were recorded at $1 \mathrm{~Hz}$. The switching sequence was S1, S2, air, and zero, with $25 \mathrm{~s}$ spent on each manifold inlet. The dripper consisted of a syringe pump and an evaporating flask. The syringe pump delivered liquid water of known isotope ratios (Std2: $-101.7 \%$ for $\delta \mathrm{D}$ and $-13.55 \%$ for $\delta^{18} \mathrm{O}$ ). It produced one calibration 
stream (S2) whose mixing ratio was about $5 \%$ high than the target water vapor mixing ratio and a second calibration stream (S1) whose mixing ratio was about $5 \%$ lower than the target. Zero calibration was accomplished with a tank of commercial dry grade air. The dry grade air may have an impurity of 10-100 ppm of vapor; this was scrubbed by a molecular sieve of water vapor. The CS measurement was calibrated every $100 \mathrm{~s}$ by a switching cycle using a two-point concentration interpolation procedure with the water vapor mixing ratio dynamically controlled to track the ambient water vapor mixing ratio. Possible delta-stretching effects were not considered.

P5 and P2 were each configured with a three-way solenoid valve, one common port, one air sample intake, and one calibration gas intake. The valve was controlled by an electric signal to switch between the air sample and the calibration sample at a preset interval. Both analyzers drew sampling air and calibration air at a flow rate of $0.03 \mathrm{~L} \mathrm{~min}^{-1} \mathrm{STP}$ and recorded the signals at about $0.2 \mathrm{~Hz}$ (Schmidt et al. 2010). The P5 analyzer was coupled with a liquid evaporator (Picarro) and a CTC Analytics PAL liquid autosampler (LEAP Technologies, Carrboro, North Carolina). Every $12 \mathrm{~h}$, the evaporator was switched on and three working water standards (Std1: $-154.1 \%$ for $\delta \mathrm{D}$ and $-19.57 \%$ for $\delta^{18} \mathrm{O}$; Std2: $-101.7 \%$ for $\delta \mathrm{D}$ and $-13.55 \%$ for $\delta^{18} \mathrm{O}$; Std3: $-9.8 \%$ for $\delta \mathrm{D}$ and $-2.96 \%$ for $\delta^{18} \mathrm{O}$ ) were injected sequentially into it. A full calibration cycle lasted about $54 \mathrm{~min}$. The moist air in the evaporator was then flushed into the analyzer's sample chamber at a fixed mixing ratio of $20 \mathrm{~mol} \mathrm{~mol}^{-1}$. The ambient measurements were corrected for the stretching of the delta scale by using a linear fit of the true versus the measured delta values of the working standards. Two of the working standards (Std1 and Std3) were supplied by one of the manufacturers (Los Gatos Research), and one (Std2) was an in-house working standard that was analyzed by the liquid water isotope analyzer (model DLT-100) with a typical instrument precision of $\pm 0.3 \%$ o for $\delta \mathrm{D}$ and $\pm 0.1 \%$ for $\delta^{18} \mathrm{O}$. To avoid the confounding effect of systematic biases between the two sets of standards, in the following only Std1 and Std3 were used to calibrate the P5 measurement.

The $\mathrm{P} 2$ analyzer was calibrated with a second dripper (dripper B). Dripper B was constructed in the same way as dripper A except that it maintained a constant water vapor mixing ratio of about $18 \mathrm{~mol} \mathrm{~mol}^{-1}$. It also used Std2 as the liquid water supply. The analyzer sampled the dripper moisture in the first $5 \mathrm{~min}$ of every hour and spent the remainder of the hour measuring the air sample. Let $R_{d}$ be the true molar ratio of $\operatorname{Std} 2, R_{d, m}$ the measured molar ratio of the dripper air, and $R_{v, m}$ the measured molar ratio of the water vapor from the air-sampling intake. The calibrated molar ratio $\left(\mathrm{D} / \mathrm{H}\right.$ or $\left.{ }^{18} \mathrm{O} /{ }^{16} \mathrm{O}\right)$ of water vapor was given by

$$
R_{v}=R_{d} \frac{R_{v, m}}{R_{d, m}},
$$

which was converted to the delta notation as

$$
\delta_{v}=\left[\left(R_{v} / R_{\mathrm{vsmow}}\right)-1\right] \times 1000 \%,
$$

where $R_{\text {vsmow }}$ is the VSMOW standard molar ratio.

The LS analyzer was also configured with a three-way solenoid valve, with one common port, one air sample intake, and one calibration gas intake. It drew the sample and calibration air at $0.3 \mathrm{~L} \mathrm{~min}^{-1} \mathrm{STP}$, and sampled the signal at about $1 \mathrm{~Hz}$, which was block averaged to $25 \mathrm{~s}$ for analysis. A portion of the dripper B air was split to its calibration gas intake. The analyzer was calibrated in an identical manner as P2 [Eqs. (1)-(2)].

\section{b. Intercomparison of four IRIS analyzers}

The experiment lasted from 21 August to 3 October 2010. It consisted of three parts, as described below. All of the definitions of meteorology terms are referenced in the International Organization for Standardization (ISO 1993, 1995; Ocheltree and Loescher 2007).

\section{1) Atmospheric MEASUREMENT}

The purpose of the atmospheric measurement was to assess the ability of these analyzers to monitor the dynamic variations occurring in the atmosphere. The $\delta^{18} \mathrm{O}$ and $\delta \mathrm{D}$ of ambient water vapor were measured simultaneously with these analyzers from 21 August to 4 September. P2 and P5 shared a common air intake, and CS and LS each had another because of their different sampling pressure limits. Both intake lines were equipped with a filter (Swagelok model B-4F-05, Connecticut Valves and Fittings, Norwalk, Connecticut) contained in an enclosure heated to $60^{\circ} \mathrm{C}$.

\section{2) BUBbLER TESTS}

A bubbler combined with dry air was used for performance evaluation from 8 September to 3 October. The bubbler was supplied with room air and produced a saturated moisture stream whose isotope compositions were computed from the Rayleigh equilibrium prediction. The bubbler air was mixed with appropriate amounts of dry air to provide a wider range of humidity than during the atmospheric measurement. The humidity was controlled at five preset levels of about 25, 20,15, 10, and $5 \mathrm{~mol} \mathrm{~mol}^{-1}$. Dry air was delivered by a tank of commercial dry grade air fitted with a molecular sieve. In one test run, the humidity of the air mixture decreased from 
the highest to the lowest level, with the measurement at each humidity level lasting $48 \mathrm{~h}$. In the second test run, the humidity was adjusted from the lowest to the highest level, each lasting $24 \mathrm{~h}$. Toward the end of the bubbler tests, the mixing ratio was adjusted to about $1.5 \mathrm{~mol} \mathrm{~mol}^{-1}$ for $4 \mathrm{~h}$ of measurement.

The bubbler was a cylindrical glass flask $(52 \mathrm{~cm}$ tall, $15-\mathrm{cm}$ diameter) and was filled to $2 / 3$ capacity with water of known isotope ratios $(-49.5 \%$ for $\delta \mathrm{D}$ and $-6.73 \%$ for $\left.\delta^{18} \mathrm{O}\right)$. Room air entered from the bottom of the water reservoir at a rate of $2 \mathrm{~L} \mathrm{~min}^{-1}$ and rose as bubbles to the top, and the moist air exiting the bubbler was mixed with an appropriate amount of dry air. Of this mixed flow, about $0.9 \mathrm{~L} \mathrm{~min}^{-1}$ was delivered to the four analyzers via a common Teflon tube, and the remaining flow was bled to the room. The bubbler temperature was maintained at $22.5^{\circ} \pm 0.6^{\circ} \mathrm{C}$, with an uncertainty of $0.6^{\circ}$ o for $\delta \mathrm{D}$ and $0.05 \%$ for $\delta^{18} \mathrm{O}$, respectively, corresponding to the temperature variations. The air delivery tubing was heated to $30^{\circ} \mathrm{C}$, minimizing the possibility of condensation. After the measurement at each preset humidity level had been completed, two water samples (each $2 \mathrm{~mL}$ ) were retrieved at random depths from the bubbler reservoir for analysis of its isotope contents on a liquid water isotope analyzer (model DLT-100). The isotope compositions of the bubbler water increased slowly and linearly, consistent with the rate of water loss of the bubbler, with time to $-46.7 \%$ for $\delta \mathrm{D}$ and $-6.05 \%$ for $\delta^{18} \mathrm{O}$ at the end of the tests on 3 October. The equilibrium vapor values increased from $-122.4 \%(\mathrm{D} / \mathrm{H})$ and $-15.6 \%\left({ }^{18} \mathrm{O} /{ }^{16} \mathrm{O}\right)$ at the beginning to $-117.5 \%$ and $-14.8 \%$ at the end of the bubbler tests.

The bubbler tests served several purposes. They broadened the humidity range of the comparison experiment beyond the range of the atmospheric measurement. During the course of 24-48 h at each set humidity level, the $\delta_{v}$ values of the bubbler moisture were quite stable, increasing by less than $0.3 \%$ for $\mathrm{D}$ and by less than $0.06 \%$ for ${ }^{18} \mathrm{O}$ according to the equilibrium calculations. The variations of the measured $\delta_{v}$ after trend removal were a measure of the instrument precision. Because the $\delta_{v}$ of the bubbler moisture was higher than the $\delta_{v}$ of the ambient vapor (by up to $83 \%$ for D and up to $13.1 \%$ or ${ }^{18} \mathrm{O}$ ) at the same level of humidity, a comparison of these two sets of measurements provided information on the delta-stretching effect. Finally, we were interested in knowing if the bubbler as a Rayleigh distillation device could be used to calibrate the IRIS measurements.

\section{3) Cross-CHECK of CALibration Methods}

The calibration methods were cross-checked in three ways. After the bubbler tests had been completed, the calibration moisture produced by dripper $\mathrm{B}$, the calibration device for LS and P2, was measured with CS and P5, and that produced by dripper A, the calibration device for CS analyzer, was measured with LS and P5. Each crosscheck lasted $24 \mathrm{~h}$.

Toward the end of the comparison experiment, a commercial vapor source (model WVISS) was available to us. It generated a standard vapor stream, in a similar manner as the drippers, with distilled water as same as the bubbler water. This vapor stream was measured with CS and LS. P5 and P2 were not used because they had difficulty drawing the vapor stream when sample pressure was less than $400 \mathrm{hPa}$. The measurement was made at five levels of water vapor mixing ratio, each consisting of two to three 1-h measurements.

A small bias existed between the two sets of working standards (sStd1 and Std3 versus Std2). In every P5 calibration cycle, a small amount of Std2 water was injected into the evaporator. Its isotopic compositions were crosschecked against Std1 and Std3. The delta values of Std2 were $-101.7 \%$ for $\delta \mathrm{D}$ and $-13.55 \%$ for $\delta^{18} \mathrm{O}$. The same water measured by P5 and calibrated against Std1 and Std3 had a mean delta value of $-100.9 \pm 0.3 \%$ (with 38 samples) for $\mathrm{D}$ and $-13.45 \pm 0.06 \%$ for ${ }^{18} \mathrm{O}$. If we were to calibrate the P5 measurement with $\mathrm{Std} 2$, its $\delta \mathrm{D}$ would decrease by $0.8 \%$ and $\delta^{18} \mathrm{O}$ would decrease by $0.10 \%$. With this bias established, any remaining differences in the observations represent the true relative accuracy among the analyzers. Note that the data presented here and in the remainder of the paper were not corrected for the relative bias between the two sets of working liquid standards.

\section{Results and discussion}

\section{a. Allan variance}

Figure 1 gives an example of Allan variance analysis of both the uncalibrated and calibrated $\delta \mathrm{D}, \delta^{18} \mathrm{O}$, and deuterium excess (d_excess $\left.=\delta \mathrm{D}-8 \delta^{18} \mathrm{O}\right)$ time series obtained with the CS, P5, P2, and LS analyzers. The measurement was made of the bubbler moisture set during the course of $48 \mathrm{~h}$ at the humidity level of $20 \mathrm{~mol} \mathrm{~mol}^{-1}$. The P5, P2, and LS analyzers were calibrated at a mixing ratio of $20-21 \mathrm{~mol} \mathrm{~mol}^{-1}$. The Allan variance analysis was used to characterize their signal noises at various time scales of integration (Werle 2011). The CS measurement was calibrated in every 100-s switching cycle. After calibration, the precision of the $\delta \mathrm{D}, \delta^{18} \mathrm{O}$, and d_excess continued to improve as the averaging interval increased (Fig. 1b). The precision of the uncalibrated P5 signals improved with an increasing averaging interval, and calibration did not change the Allan variance behavior (Figs. 1c,d). The uncalibrated P2 signals had the best precision at 20000-40000 s, 

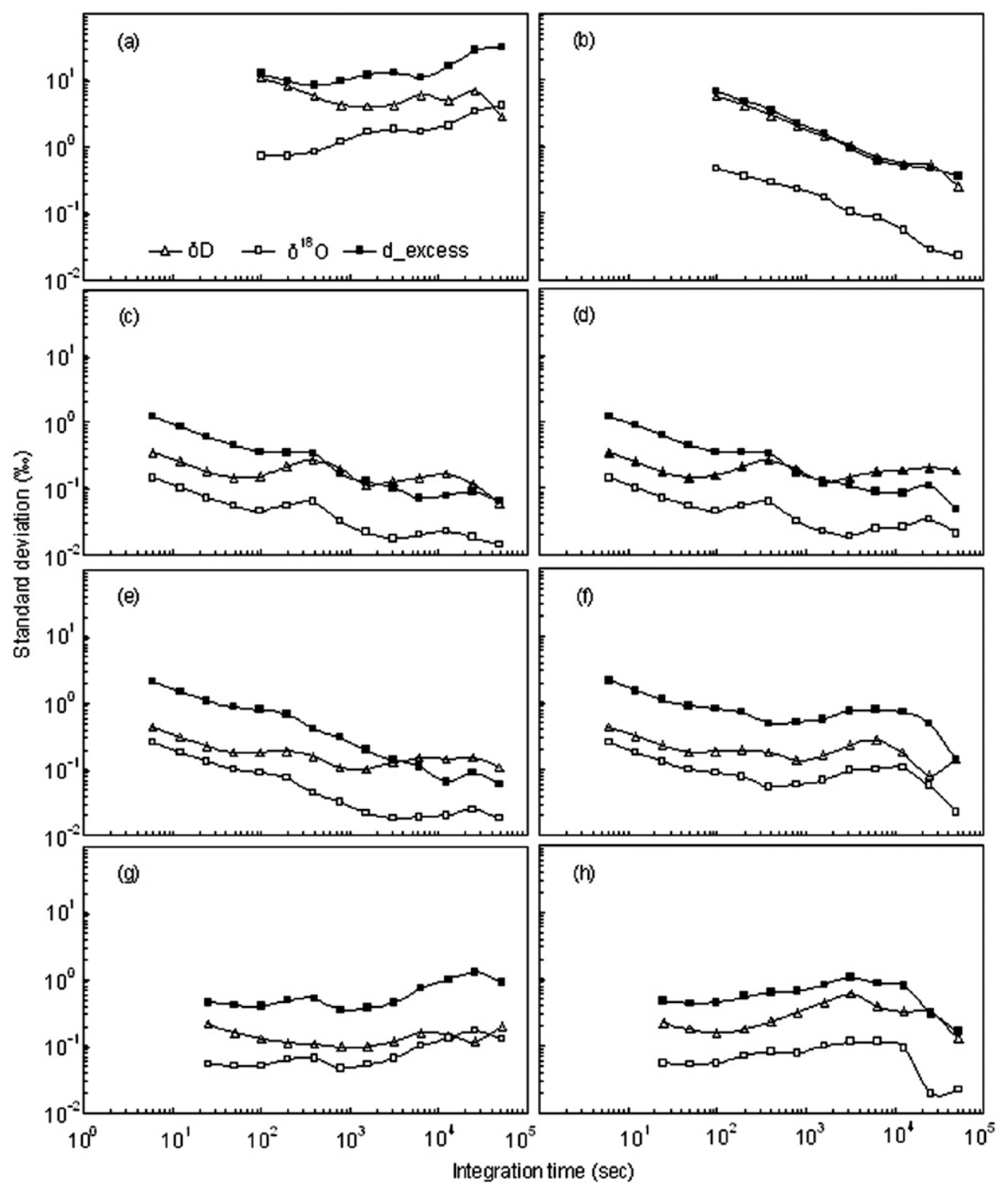

FIG. 1. Allan variance analysis of both the (left) uncalibrated and (right) calibrated isotope ratio time series at about $20 \mathrm{~mol} \mathrm{~mol}^{-1}$ during the 48-h bubbler measurements for (a),(b) CS, (c), (d) P5, (e),(f) P2, and $(\mathrm{g}),(\mathrm{h}) \mathrm{LS}$ water vapor isotope analyzers.

coinciding with the calibration interval of $1 \mathrm{~h}$. Calibration improved the P2 precision beyond $1 \mathrm{~h}$ (Figs. 1e,f). The precision of the LS analyzer did not show appreciable improvement with integration time (Fig. 1g). The factoryrecommended calibration frequency $(1 \mathrm{~h})$ brought the noise down beyond 1-h integration time, although in retrospect more frequent calibration could have brought further improvement to the measurement.

The Allan variance data shown in Figs. 1a,b are indicative of a stable performance of the CS analyzer with calibration and are consistent with the Allan variance analysis of the same analyzer 4 yr ago (Wen et al. 2008).
Dong and Baer (2010) show their obvious improvement of the LS analyzer at the humidity levels of 11 and $0.55 \mathrm{~mol} \mathrm{~mol}^{-1}$. These results suggest that Allan variance appears to be sensor specific.

\section{b. Variations among the analyzers}

Figure 2 show the time series of 1 -h- averaged $\delta \mathrm{D}$ and $\delta^{18} \mathrm{O}$ of ambient vapor measured with the four analyzers. Table 1 summarizes the relative differences of the observations shown in Fig. 2. These differences, a measure of the relative accuracy among the four analyzers, have a mean value of about $2 \%$ for $\delta \mathrm{D}$ and $0.1 \%$ 

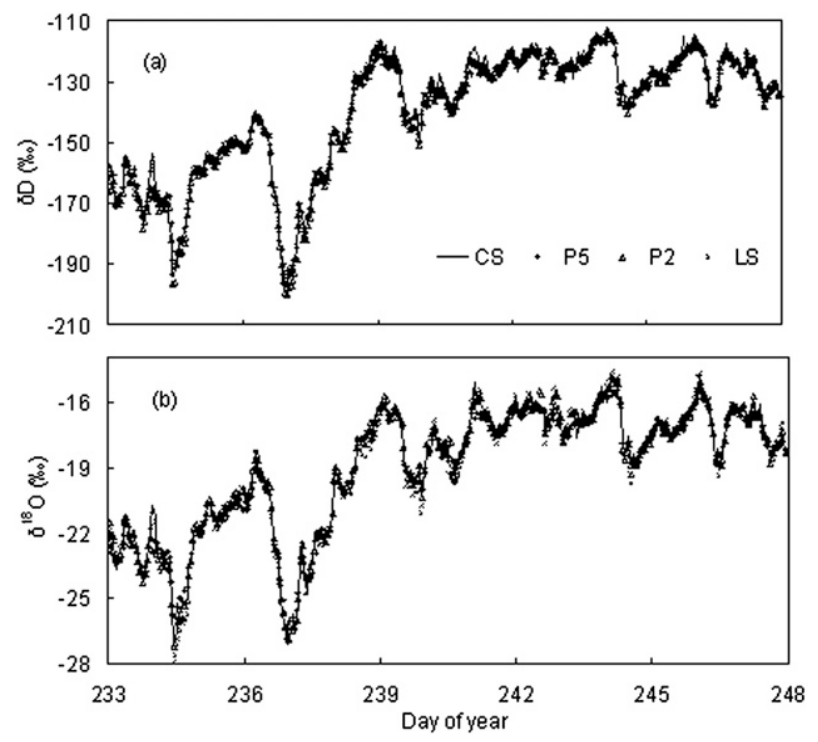

FIG. 2. Time series of 1 -h-averaged (a) $\delta \mathrm{D}$ and (b) $\delta^{18} \mathrm{O}$ of atmospheric water vapor measured with four water vapor isotope analyzers. Relative difference among the four analyzers was shown in Table 1.

for $\delta^{18} \mathrm{O}$. Two cold front events occurred in this experimental period, resulting in considerable variations in $\delta \mathrm{D}$ and $\delta^{18} \mathrm{O}$. All of the analyzers tracked the natural variability in ambient conditions extremely well.

Figure 3 illustrates the dependence on humidity of the measurements of $\mathrm{P} 5, \mathrm{P} 2$, and $\mathrm{LS}$ in reference to CS during the atmospheric measurement. The CS analyzer is used as the reference because its calibration frequency was much higher than those of the other three analyzers. The linear regression equations are also presented. The $\delta \mathrm{D}$ measurements by $\mathrm{P} 5$ and $\mathrm{P} 2$ appear independent of the mixing ratio, with the relative average differences from the CS values changing by less than $2 \%$ over the range of 14.4-27.4 mol mol${ }^{-1}$. The $\delta \mathrm{D}$ measurement by LS was negatively correlated with water vapor mixing ratio; its relative average difference from the CS measurement varied from $0.7 \%$ at $14.4 \mathrm{~mol} \mathrm{~mol}^{-1}$ to $-2.3 \%$ at $27.4 \mathrm{~mol} \mathrm{~mol}^{-1}$ according to the regression equation shown in Fig. 3. In the case of ${ }^{18} \mathrm{O}$, the relative average difference of P5, P2, and LS from CS was $0.39 \%,-0.06 \%$, and $-0.52 \%$ at $14.4 \mathrm{~mol} \mathrm{~mol}^{-1}$, respectively, and changed to $-0.43 \%, 0.10 \%$, and $0.46 \%$ at $27.4 \mathrm{~mol} \mathrm{~mol}^{-1}$, respectively. In general, P2 showed a weaker dependence on humidity than P5 and LS according to the regression equation shown in Fig. 3. The excellent mean differences shown in Table 1 are somewhat fortuitous because the calibration vapor streams had a mixing ratio that was almost centered in the range of variability of the atmospheric mixing ratio.
TABLE 1. Relative difference $(\%)$ of 1 -h-averaged $\delta \mathrm{D}$ and $\delta^{18} \mathrm{O}$ among the four analyzers during the atmospheric measurement. The mean differences and their standard deviations were calculated as the column variable minus the row variable.

\begin{tabular}{lccc}
\hline \hline$\delta \mathrm{D}$ & $\mathrm{P} 5$ & $\mathrm{P} 2$ & $\mathrm{LS}$ \\
\hline $\mathrm{CS}$ & $1.4 \pm 2.1$ & $1.3 \pm 1.8$ & $0.5 \pm 1.6$ \\
$\mathrm{P} 5$ & - & $0.0 \pm 2.0$ & $-0.9 \pm 1.8$ \\
$\mathrm{P} 2$ & - & - & $-0.8 \pm 1.6$ \\
$\delta^{18} \mathrm{O}$ & $\mathrm{P} 5$ & $\mathrm{P} 2$ & $\mathrm{LS}$ \\
$\mathrm{CS}$ & $-0.01 \pm 0.31$ & $-0.01 \pm 0.28$ & $0.07 \pm 0.32$ \\
$\mathrm{P} 5$ & - & $-0.01 \pm 0.34$ & $0.07 \pm 0.50$ \\
P2 & - & - & $0.08 \pm 0.31$ \\
\hline
\end{tabular}

\section{c. Calibration cross-checks}

Table 2 summarizes the cross-check results of the calibration devices (drippers A and B) for LS, P2, and CS. On average, the measured values of the vapor streams generated by these devices are within $2 \%$ of the $\mathrm{Std} 2 \delta \mathrm{D}$ value and within $0.1 \%$ of the $\mathrm{Std} 2 \delta^{18} \mathrm{O}$ value except for the P5 $\delta^{18} \mathrm{O}$ measurement. The P5 measurement of the ${ }^{18} \mathrm{O}$ composition of the dripper vapor streams was biased high by an average of $0.42 \%$. Of this bias, $0.10 \%$ was attributed to the bias between the two working standards (Std2 versus Std1 and Std3) and the remainder was caused by the concentration dependence problem experienced by P5. The mixing ratio $\left(20 \mathrm{~mol} \mathrm{~mol}^{-1}\right)$ at which the analyzer was calibrated did not match the mixing ratio of the vapor streams generated by the two drippers (17.1-18.2 $\mathrm{mol} \mathrm{mol}^{-1}$ ). According to the regression equation shown in Fig. 3, this mismatch translated to a systematic overestimation of $0.15 \%-0.22 \%$. Correction for these two biases would almost bring the P5 ${ }^{18} \mathrm{O}$ measurement to the acceptable uncertainty of $0.1 \%$. We conclude that the vapor streams generated by the drippers were indeed identical to the liquid water supplied in terms of isotopic compositions or, in other words, fractionations during the vapor generation process were within the error tolerances of these types of measurement.

These cross-check results show that the calibration methods (P5 discrete liquid injection versus dripper continuous flow) used here were transferrable to one another, with biases among the two methods smaller than the typical mass spectrometry precision of $2 \%$ for $\delta \mathrm{D}$ and $0.1 \%$ for $\delta^{18} \mathrm{O}$. They also underscore the importance of matching the mixing ratio of the calibration vapor stream to the mixing ratio of the target vapor being measured. Dripper devices, consisting of either a syringe pump (Lee et al. 2005; Wen et al. 2008) or a nebulizer (Iannone et al. 2010; Sturm and Knohl 2010) for water delivery and an evaporating flask supplied with dry air, have the ability to adjust dynamically to ensure 

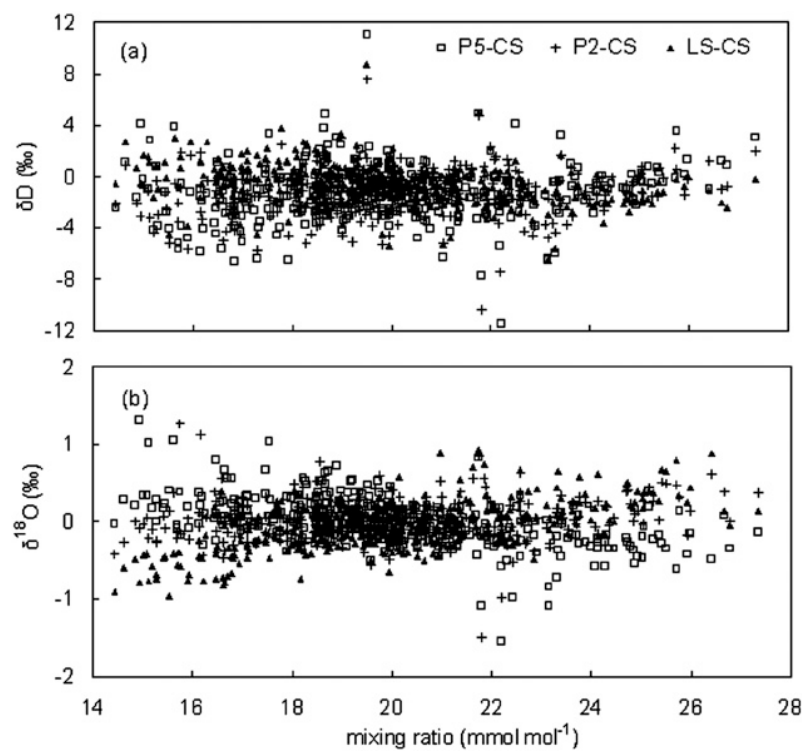

FIG. 3. Dependence on humidity of the relative difference of 1 -haveraged $\delta \mathrm{D}$ and $\delta^{18} \mathrm{O}$ measurement of atmospheric vapor. Relative difference is expressed as the difference of P5, P2, or LS from $\mathrm{CS}$. The equations are linear regression of the data for $(\mathrm{a}) \delta \mathrm{D}(\mathrm{P} 5-$ CS: $y=0.10 x-3.4, R^{2}=0.02, p=0.017$ LS - CS: $y=-0.23 x+$ $4.0, R^{2}=0.13, p<0.001 ; \mathrm{P} 2-\mathrm{CS}: y=0.10 x-3.3, R^{2}=0.02, p=$ $0.007)$ and (b) $\delta^{18} \mathrm{O}\left(\mathrm{P} 5-\mathrm{CS}: y=-0.063 x+1.3, R^{2}=0.27, p<\right.$ 0.001 ; LS - CS: $y=0.075 x-1.6, R^{2}=0.38, p<0.001 ; \mathrm{P} 2-\mathrm{CS}: y=$ $\left.0.012 x-0.23, R^{2}=0.01, p=0.034\right)$

that the generated vapor tracks the ambient water mixing ratio.

\section{d. Concentration dependence}

Three sets of measurement were used to characterize the concentration dependence behaviors of P2, P5, and LS. The problem of concentration dependence arises from the mismatch between the humidity of the calibration moisture and that of the measurement target. The concentration dependence effect of CS was not evaluated here because it had been removed by the dynamic calibration method. Figure 3 shows that the concentration dependence effect was smaller than the $2 \%$ tolerance of measurement uncertainty for $\delta \mathrm{D}$ and was greater than the $0.1 \%$ tolerance for $\delta^{18} \mathrm{O}$. We consider $2 \%$ for $\delta \mathrm{D}$ and $0.1 \%$ for $\delta^{18} \mathrm{O}$ as uncertainty tolerance because these are the typical precisions of mass spectrometry measurements. The two analyzers of the same brand (P5 and P2) show different behaviors, indicating that concentration dependence characteristics were dependent on individual sensors.

Figure 4 illustrates the dependence of the LS accuracy on humidity over the mixing ratio range of 5.3$21.9 \mathrm{~mol} \mathrm{~mol}^{-1}$. Here the measurement was made of the reference vapor generated by the commercial water source. The CS measurement shows no systematic dependence on humidity because its concentration dependence effect had been eliminated by the two-point concentration calibration procedure (Wen et al. 2008). Likewise, the $\delta \mathrm{D}$ measurement with LS showed little dependence on humidity. However, the $\delta^{18} \mathrm{O}$ measurement with LS became progressively underestimated with decreasing humidity, showing a similar trend as in Fig. 3.

Figure 5 presents the results of the bubbler tests. For clarity of presentation, the data are given as the difference of P2, P5, or LS from CS. CS was taken as a reference because its concentration dependence effect had been eliminated by the dripper calibration as discussed above. Figure 5 also includes the delta values of the bubbler vapor predicted using the Rayleigh equilibrium theory. Consistent with the patterns shown in Figs. 3 and 4 , the $\delta \mathrm{D}$ measurements were less prone to concentration dependence errors than the $\delta^{18} \mathrm{O}$ measurements. In Fig. 5a, there was no obvious dependence of $\delta \mathrm{D}$ on humidity for P5, P2, and LS. The relative difference was within the $2 \%$ threshold except for LS at $5.4 \mathrm{~mol} \mathrm{~mol}^{-1}$, which is close to the lower limit of the concentration range recommended by the manufacturer $\left(4 \mathrm{~mol} \mathrm{~mol}^{-1}\right)$. In Fig. 5b, there was stronger dependence of $\delta^{18} \mathrm{O}$ on humidity for P5 and LS than for P2. The LS behavior shown here is nearly identical to that seen in the test with the commercial vapor source (Fig. 4).

TABLE 2. Cross-validation results of the calibration devices for LS and P2 (dripper B), and for CS (dripper A). All values are shown as the measured minus Std2 standards $\left(-101.7 \%\right.$ for $\mathrm{D}$, and $-13.55 \%$ for $\left.{ }^{18} \mathrm{O}\right)$. Each value represents the mean of 24 one-hour-averaged observations.

\begin{tabular}{|c|c|c|c|c|c|c|}
\hline \multirow[b]{2}{*}{ Calibration device } & \multirow[b]{2}{*}{ Day of year } & \multirow[b]{2}{*}{ Mixing ratio $\left(\mathrm{mol} \mathrm{mol}^{-1}\right)$} & \multicolumn{2}{|c|}{ CS $(\%)$} & \multicolumn{2}{|c|}{ P5 $(\%)$} \\
\hline & & & $\delta \mathrm{D}$ & $\delta^{18} \mathrm{O}$ & $\delta \mathrm{D}$ & $\delta^{18} \mathrm{O}$ \\
\hline \multirow[t]{3}{*}{ Dripper B } & 265 & 18.2 & $-1.2 \pm 1.3$ & $-0.08 \pm 0.31$ & $0.2 \pm 0.3$ & $0.39 \pm 0.04$ \\
\hline & 275 & 17.5 & $-1.4 \pm 1.0$ & $-0.09 \pm 0.15$ & $-0.5 \pm 0.2$ & $0.36 \pm 0.04$ \\
\hline & & & \multicolumn{2}{|c|}{$\operatorname{LS}(\%)$} & \multicolumn{2}{|c|}{ P5 $(\%)$} \\
\hline Calibration device & Day of year & Mixing ratio $\left(\mathrm{mol} \mathrm{mol}^{-1}\right)$ & $\delta \mathrm{D}$ & $\delta^{18} \mathrm{O}$ & $\delta \mathrm{D}$ & $\delta^{18} \mathrm{O}$ \\
\hline \multirow[t]{2}{*}{ Dripper A } & 266 & 18.2 & $1.1 \pm 0.5$ & $0.07 \pm 0.32$ & $1.0 \pm 0.2$ & $0.47 \pm 0.07$ \\
\hline & 276 & 17.1 & $1.0 \pm 0.5$ & $-0.09 \pm 0.24$ & $0.4 \pm 0.2$ & $0.44 \pm 0.04$ \\
\hline
\end{tabular}



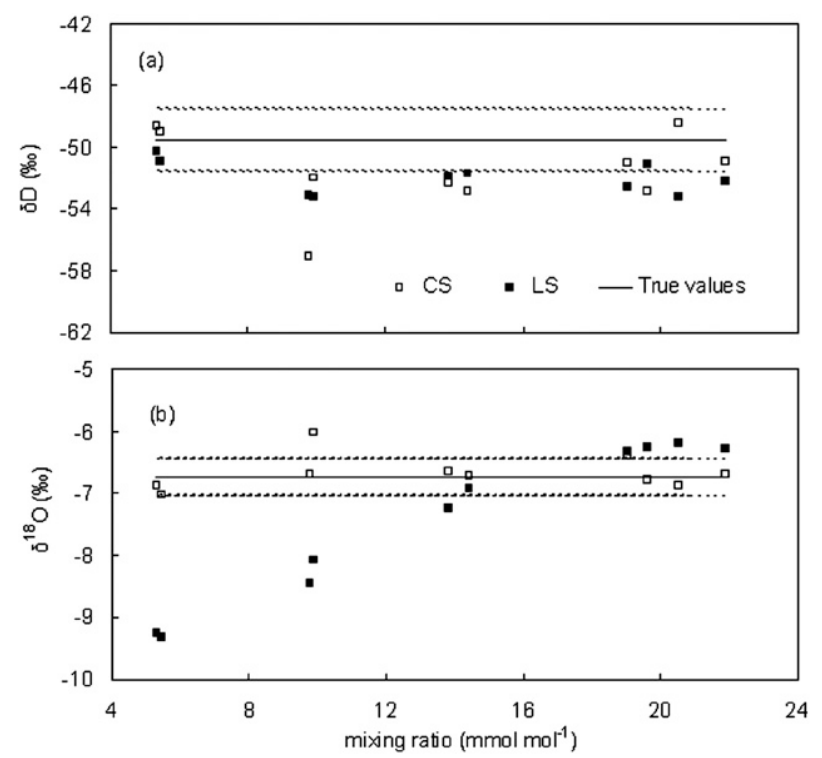

FIG. 4. One-hour-averaged (a) $\delta \mathrm{D}$ and (b) $\delta^{18} \mathrm{O}$ measured with $\mathrm{CS}$ and LS of a water vapor stream generated by a commercial reference source whose liquid water supplied had an isotopic composition of $-49.5 \pm 2 \%$ for $\delta \mathrm{D}$ and $-6.7 \pm 0.3 \%$ for $\delta^{18} \mathrm{O}$ (lines). The standard deviations of the measurements were similar to those shown in Fig. 6.

Severe concentration dependence effect is evident at the lowest mixing ratio tested in this study $\left(1.5 \mathrm{~mol} \mathrm{~mol}^{-1}\right)$. The relative difference in $\delta^{18} \mathrm{O}$ was $3.0 \%, 1.8 \%$, and $-3.3 \%$ for P2, P5, and LS, respectively, and was on the trend projected from the measurements at the higher humidity levels. Such low humidity is common near the earth's surface in mid- to high latitudes in the winter (Lee et al. 2006; Wen et al. 2010), and in the air layer above the atmospheric boundary layer (He and Smith 1999). In these environments, the mixing ratio of the calibration vapor stream should be reduced appropriately to ensure measurement accuracy.

For comparison, a concentration dependence effect of $1.6 \%\left(10 \mathrm{~mol} \mathrm{~mol}^{-1}\right)^{-1}$ for $\delta \mathrm{D}$ and $0.5 \%$ $\left(10 \mathrm{~mol} \mathrm{~mol}^{-1}\right)^{-1}$ for $\delta^{18} \mathrm{O}$ occurred in a study of liquid water measurement with a WS-CRDS analyzer (Brand et al. 2009). In another study also involving a WS-CRDS analyzer, the vapor measurements between 14 and $24 \mathrm{~mol} \mathrm{~mol}^{-1}$ require corrections by up to $0.4 \%$ for $\delta^{18} \mathrm{O}$ and $1.3 \%$ for $\delta \mathrm{D}$ (Gupta et al. 2009). A recent investigation of the concentration effects reveals a maximum error of $2.4-2.8 \%\left(\delta^{18} \mathrm{O}\right)$ and $1.2 \%(\delta \mathrm{D})$ for the vapor measurements with a WS-CRDS analyzer (Schmidt et al. 2010). A performance test of an OA-ICOS analyzer indicates that its vapor measurements require corrections by up to $5 \%$ for $\delta \mathrm{D}$ and by up to $2 \%$ for $\delta^{18} \mathrm{O}$ at $15 \mathrm{~mol} \mathrm{~mol}^{-1}$ (Sturm and Knohl 2010).

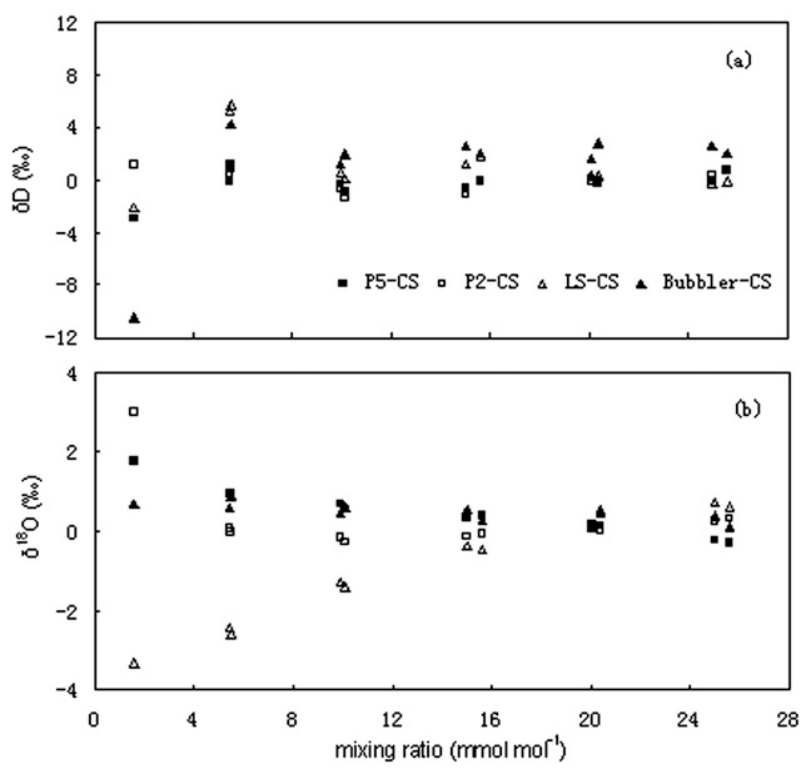

FIG. 5. As in Fig. 3, but for the bubbler vapor. Each data point represents the average difference of 24 or 48 one-hour-averaged measurements between P5, P2, or LS and CS, except those at $1.5 \mathrm{~mol} \mathrm{~mol}^{-1}$, which are averages of 4 one-hour-averaged observations. Also shown is the difference between the Rayleigh distillation prediction of the bubbler vapor delta and the CS measurement. Measurement precisions are characterized in Fig. 6.

These concentration dependence behaviors illustrate the importance of using a calibration at multiple mixing ratios to bracket the range of natural variability. In the mass spectrometer analysis, it is desirable to use multiple isotope standards to correct for the stretching of the delta scale. In the IRMS measurement scheme, the isotopologue signals are always at approximately the same levels. In real-time atmospheric measurements, the dynamic change in the mixing ratios is large and can lead to larger errors if the calibration mixing ratio is held at a fixed value (Wen et al. 2008). This can be further understood by comparing the LS atmospheric measurement and its bubbler test results. These two sets of measurements experienced very different isotope ratios, in the case of $\delta^{18} \mathrm{O}$ with atmospheric values of ranging from $-27.9 \%$ to $-14.7 \%$ and bubbler values from $-15.6 \%$ to $-14.8 \%$. The reader is reminded that LS was calibrated with a moisture stream with a fixed humidity $\left(20 \mathrm{~mol} \mathrm{~mol}^{-1}\right)$ and an isotope ratio (Std2: $-101.7 \%$ for $\delta \mathrm{D}$ and $-13.55 \%$ for $\delta^{18} \mathrm{O}$ ). The LS measurement showed a $\delta^{18} \mathrm{O}$ concentration dependence effect of 0.075 $\pm 0.01 \%$ o $\left(\mathrm{mol} \mathrm{mol}^{-1}\right)^{-1}$ according to the atmospheric data (Fig. 3). Over the same humidity range of Fig. 3, the LS measurement yielded a nearly identical concentration dependence effect of $0.11 \pm 0.06 \%\left(\mathrm{~mol} \mathrm{~mol}^{-1}\right)^{-1}$ according to the bubbler data (Fig. 5). In agreement with a previous study (Schmidt et al. 2010), our study shows 
that a calibration targeting the mixing ratio range is more important than that targeting the delta range.

\section{e. Accuracy of the Rayleigh equilibrium calculation}

Several research groups have used dewpoint generators as Rayleigh distillation devices for calibration and performance evaluation of TDLAS and OA-ICOS analyzers (Lee et al. 2005; Wen et al. 2008; Wang et al. 2009; Griffis et al. 2010). Because the size of its water reservoir is small $(\sim 30 \mathrm{~mL})$, the generated vapor can experience $\delta_{v}$ increases by as much as $23 \%$ and $3 \%$ for $\delta \mathrm{D}$ and $\delta^{18} \mathrm{O}$ over $24 \mathrm{~h}$ (Wen et al. 2008). Our bubbler had a much larger reservoir capacity $(9 \mathrm{~L})$ and its vapor delta was much more stable with time, changing by $\sim 0.2 \%$ day $^{-1}$ for $\delta \mathrm{D}$ and $\sim 0.03 \%$ day ${ }^{-1}$ for $\delta^{18} \mathrm{O}$ at an operating temperature of $22.5 \pm 0.6^{\circ} \mathrm{C}$. However, it is not known if the Rayleigh equilibrium prediction was accurate enough for calibration purposes. Over the mixing ratio range $5.4-25.6 \mathrm{~mol} \mathrm{~mol}^{-1}$, the Rayleigh $\delta \mathrm{D}$ calculation was $2.0 \pm 0.6 \%, 2.2 \pm 0.8 \%, 2.2 \pm 0.9 \%$, and 1.0 $\pm 2.0 \%$ higher than the CS, P5, P2, and LS measurements, respectively, with an overall mean difference of $1.8 \pm 2.0 \%$ (Fig. 5). In this humidity range, the $\delta \mathrm{D}$ concentration dependence errors were negligible, so the consistently high values can be considered as high bias errors of the Rayleigh calculations. These bias errors are comparable to the error tolerance of $2 \%$ for $\delta \mathrm{D}$. The large difference from the CS measurement $(4.3 \%$ ) at $5.4 \mathrm{~mol} \mathrm{~mol}^{-1}$ could be an artifact of memory effects in the process of mixing the dry air and the bubbler air.

The evaluation of ${ }^{18} \mathrm{O}$ should be restricted to the comparison with CS in order to avoid the confounding effect of concentration dependence errors of the other three analyzers. Once again, the Rayleigh calculation was biased high over the entire humidity range shown in Fig. 5. The average difference was $0.5 \pm 0.2 \%$. This difference is greater than the error tolerance of $0.1 \%$ (Wen et al. 2008). In a related study using a bubbler of similar size, the Rayleigh calculation for $\delta^{18} \mathrm{O}$ was $0.2-0.5 \%$ higher than the TDLAS measurements (Kim et al. 2007).

The systematic bias of the Rayleigh equilibrium prediction may have been caused by incomplete mixing of the reservoir water, uncertainty in the measured temperature, and a temperature gradient in the bubbler. The delta values of the duplicate liquid samples retrieved from the bubbler reservoir deviated from each other by as much as $8 \%$ for $\delta \mathrm{D}$ and $0.8 \%$ for $\delta^{18} \mathrm{O}$. Better results are achieved with a bubbler made of a thin glass tube (Iannone et al. 2010). Stirring the reservoir may also bring improvement. Absent of adequate mixing, a bubbler of our size may be an acceptable standard for $\mathrm{D}$ but not for ${ }^{18} \mathrm{O}$.
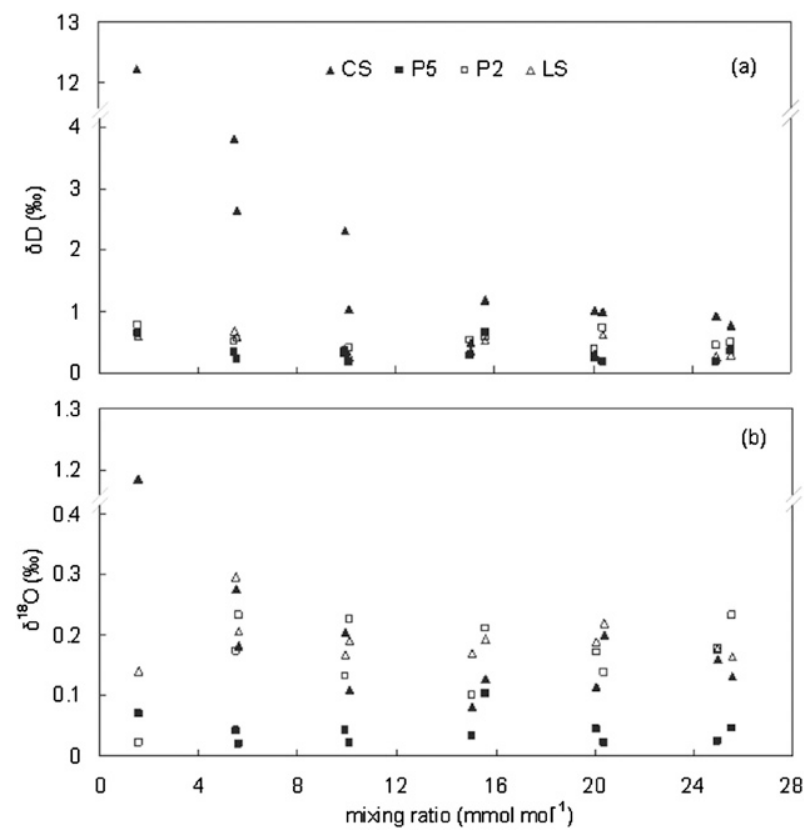

FIG. 6. Instrument precision as a function of humidity: (a) $\delta \mathrm{D}$ and (b) $\delta^{18} \mathrm{O}$. The standard deviation of the 24 or 48 one-hour-averaged measurement at every set humidity level of the bubbler tests was taken as a measure of the instrumental precision after the linear trend had been removed to account for the small increase over each test run.

\section{f. Instrument precision}

Figure 6 shows the dependence of the precision of the four analyzers on humidity during the bubbler tests. Here the standard deviation of the 24 or 48 one-houraveraged measurement at every set humidity level of the bubbler tests was taken as a measure of the instrumental precision after a small linear trend $\left(<0.06 \%\right.$ for $\delta^{18} \mathrm{O}$ and $<0.3 \%$ for $\delta \mathrm{D}$ ) over each test run had been removed. CS had the highest standard deviation for the D measurement among the four analyzers. Its precision was approximately $1 \%$ for the mixing ratio greater than $15 \mathrm{~mol} \mathrm{~mol}^{-1}$ and increased rapidly with decreasing mixing ratio to about $12 \%$ at $1.5 \mathrm{~mol} \mathrm{~mol}^{-1}$. In comparison, the D precision of the P5, P2, and LS analyzers was $\sim 0.4 \%$ and showed virtually no dependence on humidity. These noise levels were consistent with the Allan variance results (Fig. 1).

In terms of the ${ }^{18} \mathrm{O}$ measurement, the precision of both Picarro analyzers showed no dependence on humidity in the range investigated here, but differed in magnitude ( $0.04 \%$ for P5 and $0.18 \%$ for P2). CS and LS had comparable precision, and both showed a weak negative dependence on humidity. In the mixing ratio range greater than $5 \mathrm{~mol} \mathrm{~mol}^{-1}$, CS and LS had a mean precision of $0.16 \%$ and $0.20 \%$, respectively. 
The data in Fig. 4 should be interpreted with these precision values in mind. Each data point shown in Fig. 4 represents 1-h-averaged measurement. The standard deviation of all the CS measurements in Fig. 4 was $2.6 \%$ for $\mathrm{D}$ and $0.28 \%$ for ${ }^{18} \mathrm{O}$. These variations are slightly worse than the precision values shown in Fig. 6 over the mixing ratio range $5.4-25.6 \mathrm{~mol} \mathrm{~mol}^{-1}(1.5 \%$ for $\mathrm{D}$ and $0.16 \%$ or ${ }^{18} \mathrm{O}$ ).

In comparison, 1 -h-averaged $\delta^{18} \mathrm{O}$ precision of $0.09 \%$ (Lee et al. 2005) and 1-h-averaged $\delta \mathrm{D}$ and $\delta^{18} \mathrm{O}$ precision of $1.1-2.0 \%$ and $0.07-0.12 \%$ (Wen et al. 2008), respectively, were reported for our previous tests of CS analyzers. Several studies on WS-CRDS and OA-ICOS analyzers focus on the precision for liquid water (Lis et al. 2008; Berman et al. 2009; Penna et al. 2010). An analytical precision was reported to range from $\pm 0.56 \%$ o to $\pm 1.80 \%$ for $\delta \mathrm{D}$ and from $\pm 0.10 \%$ o to $\pm 0.27 \%$ o for $\delta^{18} \mathrm{O}$, with a marked difference in precision among the four liquid OA-ICOS instruments tested (Penna et al. 2010). A WS-CRDS vapor analyzer was reported to have a precision of $0.5 \%$ for $\delta \mathrm{D}$ and $0.1 \%$ for $\delta^{18} \mathrm{O}$ in the laboratory, and $1 \%$ for $\delta \mathrm{D}$ and $0.2 \%$ for $\delta^{18} \mathrm{O}$ in the field for water vapor concentrations $>5 \mathrm{~mol} \mathrm{~mol}^{-1}$, and have worse precision at lower water vapor concentrations of $<5 \mathrm{~mol} \mathrm{~mol}^{-1}$ (Gupta et al. 2009). The precision of an OA-ICOS vapor analyzer after calibration is $0.1 \%$ for $\delta^{18} \mathrm{O}$ and $1.0 \%$ for $\delta \mathrm{D}$ at 1 -h averaging intervals under ambient conditions (Wang et al. 2009). Taking into account concentration dependence as well as temperature sensitivity of their OA-ICOS vapor analyzer, Sturm and Knohl (2010) reported a long-term stability (12 days) of $0.38 \%$ for $\delta \mathrm{D}$ and $0.25 \%$ for $\delta^{18} \mathrm{O}$. The measurement precision of a dedicated research IRIS analyzer is $0.20 \%$ for $\delta^{18} \mathrm{O}$ and $0.8 \%$ for $\delta \mathrm{D}$ at a water mixing ratio of $\sim 15 \mathrm{~mol} \mathrm{~mol}^{-1}$, with an averaging time of $300 \mathrm{~s}$ (Iannone et al. 2010). These results show that the measurement precision is dependent on the measurement technology and that there are some variations among the analyzers of the same brand.

\section{Conclusions}

In this study, an intercomparison was made among one TDLAS analyzer (CS), two WS-CRDS analyzers (P2 and P5), and one OA-ICOS analyzer (LS). The four analyzers tracked the natural variability in ambient conditions extremely well. On average, the difference among these analyzers was better than $0.1 \%$ for $\delta^{18} \mathrm{O}$ and $2 \%$ for $\delta \mathrm{D}$ over the mixing ratio range of 14.4 $27.4 \mathrm{~mol} \mathrm{~mol}^{-1}$. The $\delta \mathrm{D}$ measurements of P2, P5, and LS were less prone to concentration dependence errors than the $\delta^{18} \mathrm{O}$ measurements. The concentration dependence effect of $\delta \mathrm{D}$ was usually smaller than the $2 \%$ tolerance of measurement uncertainty over the mixing ratio range of $5.4-25.6 \mathrm{~mol} \mathrm{~mol}^{-1}$. Over the same humidity range the ${ }^{18} \mathrm{O}$ concentration dependence effect was within the $0.1 \%$ tolerance level for one analyzer (P2), and was up to $0.4 \%$ for P5 and $0.6 \%$ for LS. At the lowest humidity tested (1.5 mol mol$\left.{ }^{-1}\right), \mathrm{P} 2, \mathrm{P} 5$, and LS showed ${ }^{18} \mathrm{O}$ concentration dependence effects greater than $1.8 \%$.

The 1-h-averaged precision of P2, P5, and LS for D was $\sim 0.4 \%$ and showed no dependence on humidity. The D precision of CS was $2 \%$ for water vapor concentrations $>5 \mathrm{~mol} \mathrm{~mol}^{-1}$, and increased to $12 \%$ as water vapor mixing ratio decreased to $1.5 \mathrm{~mol} \mathrm{~mol}^{-1}$. The ${ }^{18} \mathrm{O}$ precision of the two WS-CRDS analyzers showed no dependence on humidity, but differed in magnitude $(0.04 \%$ for P5 and $0.18 \%$ for P2). The two WS-CRDS analyzers of the same brand showed different precision and concentration dependence effects, indicating that the performance was dependent on individual sensors. The CS and LS analyzers had comparable precision, and both showed a weak negative dependence on humidity, with a mean of $0.16 \%$ and $0.20 \%$, respectively, over the mixing ratio range of 5.4-25.6 mol mol ${ }^{-1}$.

We showed that a calibration targeting the mixing ratio range was more appropriate than that targeting the delta range. The concentration dependence underscores the importance of using a calibration at multiple mixing ratios to bracket the range of variability in ambient conditions. Two of the calibration methods (discrete liquid injection versus continuous dripping) were transferable with each other within the error tolerance of $2 \%$ for $\delta \mathrm{D}$ and $0.1 \%$ for $\delta^{18} \mathrm{O}$. The third calibration method, which deployed the Rayleigh equilibrium calculation of a vapor stream generated by a bubbler, was accurate to about $2 \%$ for $\delta \mathrm{D}$ but was biased high by $0.5 \%$ for $\delta^{18} \mathrm{O}$.

Acknowledgments. This study was supported by the Strategic Program of Knowledge Innovation of Chinese Academy of Sciences (Grant KZCX2-EW-QN305), the National Natural Science Foundation of China (Grants 31070408, 30871485 and 30970517), the National Basic Research Program of China (Grant 2010CB833501), the Hundred Talents Program of the Chinese Academy of Sciences, the U.S. National Science Foundation (Grant ATM-0914473), and the Ministry of Education of China (Grant PCSIRT). The first author gratefully acknowledges a fellowship from the K. C. Wong Education Foundation, Hong Kong that supported his visit to Yale University.

\section{REFERENCES}

Apodaca, R. L., K. A. Simonin, K. P. Tu, R. C. Cohen, and T. E. Dawson, 2009: The evolution of capturing reliable isotopic water vapor signatures: An intercomparison of measurement 
techniques. Eos, Trans. Amer. Geophys. Union, 90 (Fall Meeting Suppl.), Abstract B52B-01.

Baer, D. S., J. B. Paul, M. Gupta, and A. O' Keefe, 2002: Sensitive absorption measurements in the near-infrared region using off-axis integrated-cavity-output spectroscopy. Appl. Phys., 75B, 261-265.

Baker, J. M., and T. J. Griffis, 2010: A simple, accurate, fieldportable mixing ratio generator and Rayleigh distillation device. Agric. For. Meteor., 150, 1607-1611.

Berman, E. S. F., M. Gupta, C. Gabrielli, T. Garland, and J. J. McDonnell, 2009: High-frequency field-deployable isotope analyzer for hydrological applications. Water Resour. Res., 45, W10201, doi:10.1029/2009WR008265.

Brand, W. A., H. Geilmann, E. R. Crosson, and C. W. Rella, 2009: Cavity ring-down spectroscopy versus high-temperature conversion isotope ratio mass spectrometry: A case study on $\delta \mathrm{D}$ and $\delta^{18} \mathrm{O}$ of pure water samples and alcohol/water mixtures. Rapid Commun. Mass Spectrom., 23, 1879-1884.

Crosson, E. R., 2008: WS-CRDS: Precision trace gas analysis and simplified sable isotope measurements. Amer. Lab., 40,37-41.

Dong, F., and D. Baer, 2010: Development and deployment of a portable water isotope analyzer for accurate, continuous and high-frequency oxygen and hydrogen isotope measurements in water vapor and liquid water. European Geophysical Union General Assembly 2010, Vol. 12, Vienna, Austria, European Geophysical Union, Geophysical Research Abstract EGU2010-5571. [Available online at http://meetingorganizer. copernicus.org/EGU2010/EGU2010-5571.pdf.]

Dyroff, C., D. Fütterer, and A. Zahn, 2010: Compact diode-laser spectrometer ISOWAT for highly sensitive airborne measurements of water-isotope ratios. Appl. Phys., 98B, 537-548.

Galewsky, J., D. Noone, Z. Sharp, and J. Woerden, 2009: Water vapor isotopes measurements at Mauna Loa, Hawaii: Comparison of laser spectroscopy and remote sensing with traditional methods, and the need for ongoing monitoring. European Geophysical Union General Assembly 2009, Vol.11, Vienna, Austria, EGU, Geophysical Research Abstracts EGU2009-11440. [Available online at http://meetingorganizer. copernicus.org/EGU2009/EGU2009-11440.pdf.]

Gat, J. R., 1996: Oxygen and hydrogen isotopes in the hydrologic cycle. Annu. Rev. Earth Planet. Sci., 24, 225-262.

Gonfiantini, R., 1984: Stable isotope reference samples for geochemical and hydrochemical investigations. International Atomic Energy Agency, Advisory Group Meeting Rep., 81 pp.

Griffis, T. J., and Coauthors, 2010: Determining the oxygen isotope composition of evapotranspiration using eddy covariance. Bound.-Layer Meteor., 137, 307-326.

Griffith, D. W. T., I. Jamie, M. Esler, S. R. Wilson, S. D. Parkes, C. Waring, and G. W. Bryant, 2006: Real-time field measurements of stable isotopes in water and $\mathrm{CO}_{2}$ by Fourier transform infrared spectrometry. Isot. Environ. Health Stud., 42, 9-20.

Gröning, M., 2004: International stable isotope reference materials. Handbook of Stable Isotope Analytical Techniques, P. A. De Groot, Ed., Elsevier, 874-906.

Gupta, P., D. Noone, J. Galewsky, C. Sweeney, and B. H. Vaughn, 2009: Demonstration of high-precision continuous measurements of water vapor isotopologues in laboratory and remote field deployments using wavelength-scanned cavity ring-down spectroscopy (WS-CRDS) technology. Rapid Commun. Mass Spectrom., 23, 2534-2542.

He, H., and R. B. Smith, 1999: Stable isotope composition of water vapour in the atmospheric boundary layer above the forests of New England. J. Geophys. Res., 104, 11 657-11 673.
Helliker, B., and D. Noone, 2010: Novel approaches to monitoring of water vapor isotope ratios: Plants, satellites and lasers. Isoscapes: Understanding Movement, Patterns, and Process on Earth through Isotope Mapping, J. West et al., Eds., Springer, $71-88$.

Hut, G., 1987: Stable isotope reference samples for geochemical and hydrological investigations. International Atomic Energy Agency, Consultants Group Meeting Rep., 44 pp.

Iannone, R. Q., and Coauthors, 2009: Development and airborne operation of a compact water isotope ratio infrared spectrometer. Isot. Environ. Health Stud., 45, 303-320.

—, D. Romanini, O. Cattani, H. A. J. Meijer, and E. R. T. Kerstel, 2010: Water isotope ratio $\left(\delta^{2} \mathrm{H}\right.$ and $\left.\delta^{18} \mathrm{O}\right)$ measurements in atmospheric moisture using an optical feedback cavity enhanced absorption laser spectrometer. J. Geophys. Res., 115, D10111, doi:10.1029/2009JD012895.

ISO, 1993: International Vocabulary of Basic and General Terms in Meteorology. International Organization for Standardization, $60 \mathrm{pp}$.

_ 1995: Guide to the Expression of Uncertainty in Measurement. International Organization for Standardization, $101 \mathrm{pp}$.

Kerstel, E. R. T., and L. Gianfrani, 2008: Advances in laser-based isotope ratio measurements: Selected applications. Appl. Phys., 92B, 439-449.

- , R. Q. Iannone, M. Chenevier, S. Kassi, H.-J. Jost, and D. Romanini, 2006: A water isotope $\left({ }^{2} \mathrm{H},{ }^{17} \mathrm{O}\right.$, and $\left.{ }^{18} \mathrm{O}\right)$ spectrometer based on optical feedback cavity-enhanced absorption for in situ airborne applications. Appl. Phys., 85B, $397-406$.

Kim, K., X. Lee, and L. R. Welp, 2007: Transition of the isotopic composition of leaf water to the isotopic steady state in soybeans and corns. Eos, Trans. Amer. Geophys. Union, 88 (Fall Meeting Suppl.), Abstract B13B-1200.

Lee, X., S. Sargent, R. Smith, and B. Tanner, 2005: In situ measurement of the water vapor ${ }^{18} \mathrm{O} /{ }^{16} \mathrm{O}$ isotope ratio for atmospheric and ecological applications. J. Atmos. Oceanic Technol., 22, 555-565.

- R. Smith, and J. Williams, 2006: Water vapour ${ }^{18} \mathrm{O} /{ }^{16} \mathrm{O}$ isotope ratio in surface air in New England, USA. Tellus, 58B, 293-304.

Lis, G., L. I. Wassenaar, and M. J. Hendry, 2008: High-precision laser spectroscopy $\mathrm{D} / \mathrm{H}$ and ${ }^{18} \mathrm{O} /{ }^{16} \mathrm{O}$ measurements of microliter natural water samples. Anal. Chem., 80, 287-293.

Ocheltree, T. W., and H. W. Loescher, 2007: Design of the AmeriFlux portable eddy covariance system and uncertainty analysis of carbon measurements. J. Atmos. Oceanic Technol., 24, 1389-1407.

Penna, D., and Coauthors, 2010: On the reproducibility and repeatability of laser absorption spectroscopy measurements for $\delta^{2} \mathrm{H}$ and $\delta^{18} \mathrm{O}$ isotopic analysis. Hydrol. Earth Syst. Sci., 14, 1551-1566.

Sayres, D. S., and Coauthors, 2009: A new cavity based absorption instrument for detection of water isotopologues in the upper troposphere and lower stratosphere. Rev. Sci. Instrum., 80, 044102, doi:10.1063/1.3117349.

Schmidt, M., K. Maseyk, C. Lett, P. Biron, P. Richard, T. Bariac, and U. Seibt, 2010: Concentration effects on laser-based $\delta^{18} \mathrm{O}$ and $\delta^{2} \mathrm{H}$ measurements and implications for the calibration of vapour measurements with liquid standards. Rapid Commun. Mass Spectrom., 24, 3553-3561.

Sturm, P., and A. Knohl, 2010: Water vapor $\delta^{2} \mathrm{H}$ and $\delta^{18} \mathrm{O}$ measurements using off-axis integrated cavity output spectroscopy. Atmos. Meas. Tech., 3, 67-77. 
Wang, L. X., K. K. Caylor, and D. Dragoni, 2009: On the calibration of continuous, high-precision $\delta^{18} \mathrm{O}$ and $\delta^{2} \mathrm{H}$ measurements using an off-axis integrated cavity output spectrometer. Rapid Commun. Mass Spectrom., 23, 530-536.

Wen, X. F., X. M. Sun, S. C. Zhang, G. R. Yu, S. D. Sargent, and $\mathrm{X}$. Lee, 2008: Continuous measurement of water vapor $\mathrm{D} / \mathrm{H}$ and ${ }^{18} \mathrm{O} /{ }^{16} \mathrm{O}$ isotope ratios in the atmosphere. J. Hydrol., 349, 489-500.

_, S. C. Zhang, X. M. Sun, G. R. Yu, and X. Lee, 2010: Water vapor and precipitation isotope ratios in Beijing, China. J. Geophys. Res., 115, D01103, doi:10.1029/2009JD012408.
Werle, P., 2011: Accuracy and precision of laser spectrometers for trace gas sensing in the presence of optical fringes and atmospheric turbulence. Appl. Phys., 102B, 313-329.

West, A. G., G. R. Goldsmith, P. D. Brooks, and T. E. Dawson, 2010: Discrepancies between isotope ratio infrared spectroscopy and isotope ratio mass spectrometry for the stable isotope analysis of plant and soil waters. Rapid Commun. Mass Spectrom., 24, 1948-1954.

Yakir, D., and S. L. Sternberg, 2000: The use of stable isotopes to study ecosystem gas exchange. Oecologia, 123, 297-311. 